\title{
INTELECTUAIS, EDUCAÇÃO ESCOLAR E HEGEMONIA: ANÁLISE DAS FORMULAÇÕES EMPRESARIAIS SOBRE TRABALHO DOCENTE
}

\author{
André Silva Martins ${ }^{1}$ \\ Leonardo Docena Pina ${ }^{2}$ \\ Lúcia Aparecida de Ávila ${ }^{3}$ \\ Raiza Dias de Almeida ${ }^{4}$
}

\section{RESUMO}

O texto aborda o tema "intelectuais, educação escolar e hegemonia" a partir da análise das formulações, sobre trabalho docente na educação básica, elaboradas por organizações empresariais brasileiras na primeira década do século XXI. Para tanto, recorremos à análise de publicações impressas e digitais de autoria de pessoas e organizações da classe empresarial, além de documentos oficiais da política de educação. O estudo revela que, na concepção empresarial, o trabalho docente é desfigurado em sua natureza e especificidade e, assim, configura-se como obstáculo aos pressupostos da educação emancipatória ao ser convertido em estratégia de controle político e social.

Palavras-chave: Intelectuais; Hegemonia; Educação escolar; Empresários.

\section{INTELLECTUALS, SCHOOL EDUCATION AND HEGEMONY: ANALYSIS OF BUSINESS FORMULATIONS ABOUT TEACHING WORK}

\begin{abstract}
The text discusses the "intellectuals, school education and hegemony" from analysis of formulations about teaching work produced by businessmen during first decade of $21 \mathrm{st}$ century in Brazil. For it, we analyzed publications produced by people and organizations of business class. Besides, we analyzed official documents of education policy. We demonstrated that, in the business view, the teaching work got new nature and specificity. Like this, doesn't binds to the emancipatory education and turns into strategy of politic and social control.
\end{abstract}

Key-words: Intellectuals; Hegemony; School education; Businessman.

No curso das reformas educativas dos anos de 1990, cresceram as formulações sobre o trabalho do professor da educação básica. Reconhecendo a importância da classe empresarial na definição das políticas de educação no Brasil, buscamos analisar as formulações e propostas desta classe sobre o trabalho docente, procurando apreender seus significados. Assim, os objetivos do estudo se concentram na apreensão e análise: (a) da concepção empresarial sobre trabalho docente; (b) das estratégias e táticas de afirmação de tal concepção no Brasil, considerando as repercussões nas políticas públicas de educação e na educação escolar. Procuramos apreender a concepção da classe empresarial a partir do estudo de fontes documentais: publicações impressas e digitais relacionadas ao trabalho docente, incluindo artigos, livros, relatórios, entrevistas, dentre outros documentos de autoria de pessoas e organizações da classe empresarial. Também recorremos a documentos oficiais da política de educação. 
Partimos do entendimento de que, ao final dos anos de 1990 e, sobretudo, nos anos iniciais do século XXI, o empresariado brasileiro, rearticulado politicamente, passou a atuar de forma mais incisiva nas relações de hegemonia (NEVES, 2005). Por hegemonia, segundo Gramsci (2000), entende-se um complexo processo de dominação, vinculado ao exercício do poder na sociedade de classes, que se expressa a partir de ações que buscam subordinar, em termos morais e intelectuais, toda a sociedade a uma concepção particular de mundo. A questão fundamental traduzida pelo conceito de hegemonia é o processo educativo pelo qual uma classe ou fração de classe tem a capacidade de transformar suas ideias e concepções particulares em referência aceita por todos. A configuração de uma Nova Pedagogia da Hegemonia expressa, portanto, a investida empresarial nas relações de poder, caracterizada pelo processo de refinamento de antigas iniciativas e de definição de novas estratégias para o exercício da dominação (NEVES, 2005).

No campo da educação escolar, as bases do projeto educativo da classe empresarial para o século XXI passaram a demandar a criação ou formação de novos intelectuais individuais e coletivos (pessoas, institutos e fundações), responsáveis por organizar, elaborar e difundir sua concepção pelo conjunto da sociedade. Fundação Itaú Social, Fundação Vale, Fundação Lemann, CENPEC, Fundação Victor Civita, Todos pela Educação, Confederação Nacional das Indústrias e Parceiros da Educação são alguns dos aparelhos privados de hegemonia da classe empresarial que têm atuado no processo de construção da nova sociabilidade, razão pela qual optamos, neste trabalho, por recorrer à análise de suas formulações.

A partir da ideologia da responsabilidade social - um constructo que mobiliza e orienta o empresariado para intervir nas questões sociais por diferentes meios em nome do chamado "bem comum" - a classe empresarial, não só formulou um projeto de educação escolar, como, também, tem buscado influenciar as políticas públicas e as práticas pedagógicas desenvolvidas nas escolas públicas brasileiras (MARTINS, 2009).

Tendo em vista a necessidade de elucidar as implicações dessas ações empresariais para a formação humana, o presente texto se propõe a discutir o pensamento pedagógico empresarial (a condensação de ideias e concepções que subsidiam as suas estratégias de ação) com a expectativa de contribuir para alimentar as reflexões e construções críticas sobre a educação destinada à classe trabalhadora no Brasil contemporâneo.

Além desta introdução, o artigo apresenta mais quatro partes. Na primeira seção, delimitamos a concepção de trabalho educativo na perspectiva elaborada, inicialmente, por Dermeval Saviani. Posteriormente, analisamos o contexto educacional de mobilização empresarial na educação. Na seção seguinte, refletimos sobre as formulações empresariais acerca do trabalho educativo, procurando apontar o significado de tais formulações. Por fim, apresentamos algumas considerações finais.

\section{Trabalho educativo: natureza e especificidade}

Para problematizar as formulações empresariais sobre o trabalho educativo, julgamos necessário conceituar primeiramente o que seja trabalho. Essa delimitação cumpre a finalidade de apresentar a base teórica da análise com a qual operamos para interpretar o pensamento pedagógico empresarial. Os fundamentos dos conceitos estão alicerçados na concepção de trabalho em Marx (1983) e nas concepções de trabalho educativo e de educação, sistematizadas por Saviani (2005).

Compreendemos que os seres humanos necessitam construir permanentemente suas condições de existência e, nesse processo, produzem relações sociais específicas. Enquanto os outros animais vivem nos limites da natureza, os humanos possuem a capacidade de 
transformá-la, ultrapassando o plano imediato de sua determinação biológica para produzir as novas condições de vida, agindo de forma intencional e distinta das ações dos demais animais. Nesse processo, produz o que se denomina cultura.

A capacidade de agir de forma intencional, a partir das elaborações cognitivas superiores, Marx (1983, p.149-150) define como trabalho:

\begin{abstract}
Pressupomos o trabalho numa forma em que pertence exclusivamente ao homem. Uma aranha executa operações semelhantes às do tecelão, e a abelha envergonha mais de um arquiteto humano com a construção dos favos de suas colméias. Mas o que distingue, de antemão, o pior arquiteto da melhor abelha é que ele construiu o favo em sua cabeça antes de construí-la em cera. No fim do processo de trabalho obtém-se um resultado que já no início deste existiu na imaginação do trabalhador, e, portanto, idealmente.
\end{abstract}

Segundo ele, "O trabalho é um processo entre o homem e a natureza, um processo em que o homem, por sua própria ação, media, regula e controla seu metabolismo com a natureza" (MARX, 1983, p. 150). A intervenção intencional sobre a natureza, além de gerar a mudança sobre o meio, produz outro tipo de implicação significativa: a transformação do próprio ser que trabalha. Para Marx (1983, p. 150), "ao atuar, por meio desse movimento sobre a natureza externa a ele e ao modificá-la, ele modifica, ao mesmo tempo, sua própria natureza".

Partindo dessa delimitação geral, cabe ressaltar que a produção das condições de existência por meio do trabalho se vincula à educação. É justamente o fenômeno educativo que medeia a superação da determinação biológica do ser em direção à sua condição cultural. Por diferentes processos, o sujeito cria e se apropria das referências culturais para se tornar capaz de atuar nos processos de produção da existência social. Isso significa que a educação é inerente ao ser humano, sendo necessária à transformação do ser biológico em ser cultural. Entre trabalho e educação existe, pois, um nexo orgânico vital.

Porém, como processo de formação cultural, sob as mediações das relações de poder, o fenômeno educativo assumiu formas específicas ao longo do tempo. Destaca-se, nesse processo, a forma institucionalizada denominada escola, uma resposta à complexificação da produção da vida por meio do trabalho.

A instituição escolar assumiu a função de viabilizar a formação intelectual e moral conforme as referências de certo tempo histórico. Sua generalização e legitimação correspondem ao reconhecimento, ainda que contraditório, de que para estar no mundo e viver coletivamente se tornou indispensável certo domínio de códigos culturais. A escola, portanto, é uma instituição que se configurou a partir das mudanças da produção da existência; "Em conseqüência, o saber metódico, sistemático, científico, elaborado passa a predominar sobre o saber espontâneo, 'natural', assistemático, resultando daí que a especificidade da educação passa a ser determinada pela forma escolar" (SAVIANI, 2005, p. 8).

A educação escolar se constituiu por meio do trabalho educativo ou trabalho pedagógico, realizado por um trabalhador específico: o professor (SAVIANI, 2005). Segundo Saviani (2005), essa forma específica de trabalho possui duas características: é imaterial e complexo. Imaterial porque seu produto se vincula à produção de ideias, conceitos, símbolos, habilidades, entre outros, envolvendo elevado grau de subjetividade. E complexo porque exige funções intelectuais superiores, envolvendo o domínio de conhecimentos e metodologias específicas. 
Além disso, o trabalho pedagógico é similar, em certos aspectos, ao trabalho artesanal. A similaridade corresponde ao grau de liberdade e autonomia do professor no processo educativo e à imprevisibilidade do resultado de seu trabalho, uma vez que ensinar constitui um processo aberto: cada ato é marcado pela singularidade das relações com os sujeitos da aprendizagem - os estudantes.

O trabalho educativo envolve identificação, seleção e socialização do conhecimento sistematizado que precisa ser dominado pelo seres humanos para que eles se tornem sujeitos de seu tempo, capazes de atuar coletivamente na produção da existência. Portanto, a finalidade do trabalho educativo é "[...] produzir, direta e intencionalmente, em cada indivíduo singular, a humanidade que é produzida histórica e coletivamente pelo conjunto dos homens." (SAVIANI, 2005, p. 13). Seu desenvolvimento pressupõe a relação com os estudantes e abrange atividades específicas e especializadas que marcam sua identidade. Os atos de planejar, ministrar aulas, avaliar o processo de aprendizagem que, em conjunto, articulam-se à mobilização dos estudantes, constituem a especificidade desse trabalho.

Apesar disso, o trabalho educativo não é livre na sociedade capitalista. Está subordinado às leis que regem o trabalho em geral; subordinado, portanto, à divisão social e técnica do trabalho.

Considerando que o conhecimento constituiu nas sociedades modernas uma das principais forças produtivas, além de potencializar a compreensão das relações sociais e de poder, os proprietários dos meios de produção estabeleceram formas de controle do conhecimento, por entendê-lo como propriedade exclusiva de sua classe. Inserido nessa dinâmica, o trabalho pedagógico foi historicamente instruído para distanciar o conhecimento sistematizado das necessidades humanas reais, sugerindo que o domínio mais elevado do conhecimento sistematizado fosse algo dispensável a todos. Com efeito, sob a orientação de uma concepção conservadora de formação humana, o trabalho pedagógico na educação pública se concentrou mais na disciplina e no controle das subjetividades do que na mediação entre sujeito, conhecimento e realidade.

Expropriado dos meios de trabalho, os professores ficaram vulneráveis frente às orientações do pensamento conservador, cujo entendimento é o de que, para as massas, caberia uma escolarização restrita, centrada na transmissão do mínimo, ou seja, apenas do conhecimento tido como indispensável para a venda de sua força de trabalho nas relações sociais capitalistas. Contudo, uma vez que a escola é contraditória, muitos professores, resistem às orientações dominantes, mesmo em condições adversas, para se filiar às perspectivas críticas de formação humana. Nos anos mais recentes de nossa história, essa tensão foi desequilibrada pelas ações empresariais e pelas políticas públicas, exigindo uma reflexão sobre o significado dessas intervenções do empresariado.

\section{A configuração do trabalho educativo na realidade brasileira}

Após o impeachment do presidente Fernando Collor de Melo em 1992, fenômeno que obrigou a reorganização das forças políticas na constituição do governo, e com a instalação do mandato "tampão" da gestão Itamar Franco, os preceitos neoliberais passaram a fundamentar as políticas econômicas e sociais, produzindo efeitos significativos na educação escolar.

Nesses períodos de governo, a questão educacional foi conduzida consoante às orientações internacionais pactuadas na Declaração Mundial de Educação para Todos, gerada na Conferência Mundial de Educação para Todos, ocorrida em março de 1990, sob a direção da UNESCO, UNICEF e Banco Mundial. Nessa linha, em 1993, o governo, implementou o chamado Plano Decenal de Educação para Todos (PDET), numa clara e 
direta vinculação ao acordo internacional e em solene desrespeito à Constituição Federal que previa o estabelecimento de um Plano Nacional de Educação para o país, envolvendo o conjunto da educação nacional. Mesmo assim, o tema "valorização do professor" ganhou destaque.

Indubitavelmente, a política governamental de valorização do professor tinha um apelo à unidade política entre governo e professores. No entanto, ultrapassando o plano das aparências, observamos que a formulação governamental foi inconsistente em vários aspectos, comprometendo sua viabilidade.

Cabe registrar que o PDET, além de se apoiar nas diretrizes internacionais, baseouse nos subsídios ofertados pelo Fórum Nacional - espaço de articulação político-ideológica criado em 1988 por setores do empresariado no Brasil com a finalidade de refletir sobre os problemas nacionais e oferecer soluções para o país, funcionando como um think tank ${ }^{5}$. O Fórum também defendia a ampliação de acesso ao ensino fundamental, mas vinculava a educação ao fortalecimento da economia nacional e à inserção do país no mercado internacional. O que estava em jogo, na visão do Fórum e do governo, era a educação como fator de desenvolvimento de capital humano. A síntese de um dos integrantes do INAE sobre o PDET e o projeto de desenvolvimento brasileiro instituído no governo Itamar Franco é bem ilustrativa:

Conclui-se, assim, que se forma no país crescente convergência de idéias e de propósitos com relação à importância da educação para o desenvolvimento e com respeito aos caminhos a percorrer, para que a escola preencha o papel que dela se espera na construção de uma sociedade mais eficiente, mais justa e mais livre (ALBUQUERQUE, 1993, p.66).

Verificamos que os enunciados de "sociedade mais eficiente, mais justa e mais livre" equivalem às assertivas do Consenso de Washington e de Hayek (1987) na defesa do neoliberalismo.

Apesar de toda repercussão midiática e mobilização das instâncias da aparelhagem estatal, as consequências concretas do PDET não foram significativas para alterar o cenário educacional do país. No entanto, evidenciou as opções das forças políticas dominantes, principalmente sobre os limites da suposta valorização do magistério.

Após a eleição presidencial de 1994, instalado o governo Fernando Henrique Cardoso (FHC), o bloco no poder deu curso às medidas inicialmente delineadas pelo governo anterior. Nesse novo período, a marca do modelo gerencial de ordenamento do Estado e das políticas sociais se tornou mais evidente.

Sob bases políticas mais sólidas, o governo FHC implementou várias mudanças na educação consoante as orientações internacionais que previam a focalização da política de educação no ensino fundamental. Ao longo de dois mandatos, tal governo conseguiu introduzir mudanças importantes na educação do país que, de modo direto ou indireto, repercutiram no trabalho educativo. Entre elas, destacamos a massificação do ensino fundamental de oito anos em detrimento da democratização do acesso e permanência. Para sustentar essa orientação segundo os preceitos gerencialistas, o governo instituiu o Fundo Nacional de Desenvolvimento da Educação (FUNDEF) em 1996 e estabeleceu os Parâmetros Curriculares Nacionais $(\mathrm{PCN})$, em 1997, para a $1^{\mathrm{a}}$ a $4^{\mathrm{a}}$ série do ensino fundamental e, em 1998, para a $5^{\text {a }}$ a $8^{\text {a }}$ do mesmo nível de ensino. Além disso, criou programas que padronizaram os modelos pedagógicos e administrativos, reduzindo as escolas a instâncias de execução das formulações elaboradas pelo núcleo estratégico de governo. Entre eles, destacamos o Programa Dinheiro Direto na Escola (SANTOS, 2006). 
O Brasil entrou no século XXI com o ensino fundamental praticamente universalizado e com expansão significativa de matrículas no ensino médio sem alterar o patamar de qualidade da formação realizada. Nesse período, a avaliação em larga escala foi instituída como parâmetro de aferimento da qualidade. Sobre o financiamento, predominou a ideia de que não havia falta de recursos para educação, mas, sim, má gestão.

O governo brasileiro, ao longo dos anos, concebeu a questão educacional como meio de preparação para a empregabilidade e para a disciplina social dos mais explorados, secundarizando a questão da qualidade (OLIVEIRA, 2004). Isso significou que a ampliação de acesso à educação registrada nos anos de 1990, ao invés de assegurar direitos, limitou-se a conquistar bases políticas e sociais para a manutenção do exercício da hegemonia burguesa no Brasil.

Os preceitos gerencialistas, fundamentados no projeto neoliberal da terceira via, passaram a ordenar a gestão da educação pública, em geral, e da força de trabalho em particular. O protagonismo da classe empresarial no tratamento das questões sociais se consolidou como marca do período. Sob o argumento de que a modernização do Estado exigia maior participação de todos no provimento das questões sociais, a classe empresarial, regida organicamente pela ideologia da responsabilidade social e por meio de suas organizações, passou a intervir diretamente no ordenamento da educação pública brasileira. $\mathrm{O}$ argumento difundido era que, ao invés de um Estado provedor, a sociedade é que deveria se tornar provedora. A criatividade e a experiência empresarial, somadas à energia da "cidadania ativa" - os cidadãos voluntários -, passaram a ser apontadas como a força política da mudança na educação pública do país.

A classe empresarial, orientada pelo Instituto Ethos de Responsabilidade Social e pelo Grupo de Institutos, Fundações e Empresas (GIFE), organismos de síntese ideológica, verdadeiros aparelhos privados de hegemonia, passou a desempenhar um novo papel político na educação escolar brasileira. Com essa identidade político-ideológica, tal classe não só executou ações diretas em redes de ensino e/ou unidades escolares, como também passou a intervir na definição das políticas de educação em estados e municípios da federação, com o apoio do governo FHC.

A partir de 2003, com a vitória eleitoral da candidatura Lula e com a instalação do novo governo, o projeto das forças políticas neoliberais parecia ter sido derrotado. No entanto, as expectativas de mudanças foram frustradas, inclusive em relação à política educacional. O novo governo, alinhado à hegemonia burguesa, realizou apenas algumas inflexões no modus operandi governamental, passando a valorizar os temas sociais e ampliando a participação opinativa das organizações sobre temas de relevância nacional. $O$ modelo gerencial de Estado não foi revisto, mas, sim, aperfeiçoado com verniz social. $\mathrm{O}$ balanço do período revela que a diferença entre o governo FHC e o governo Lula foi de ênfase e não de projeto.

Em relação à questão educacional, os empresários assumiram um papel de maior destaque, na medida em que, além de manter a influência nas políticas educacionais de estados e municípios, por meio de convênios com órgãos públicos, passaram a intervir diretamente na formulação das políticas no interior do Ministério da Educação (MEC). Entre várias evidências, destacamos a participação dos empresários na definição do Plano de Desenvolvimento da Educação (PDE); na intervenção do delineamento do Plano de Metas Compromisso Todos pela Educação (MALINI, 2009) e na coordenação de programas do MEC.

Analisando o pensamento pedagógico da classe empresarial, orientado pela ideologia da responsabilidade social, verificamos uma articulação em dois planos. No plano éticopolítico, fundamentado na teoria do capital social, visa a orientar a formação dos filhos da 
classe trabalhadora dentro dos referenciais do novo padrão de sociabilidade burguesa. No plano técnico-científico, fundamentado na atualização da teoria do capital humano, busca desenvolver habilidades e competências instrumentais, tendo em vista a transformação dos estudantes em "mão de obra". Essas projeções passaram a exigir o reordenamento do trabalho docente, de que trataremos na próxima seção.

\section{Formulações empresariais sobre o trabalho educativo}

As entidades empresariais defendem que a eficiência educacional do setor público depende de aplicação de procedimentos gerenciais modernos. A despeito dos fatores que configuraram a realidade educacional do país, acreditam que a racionalidade do mundo dos negócios, emprestada à educação, seria a chave do sucesso. Além de alterar as práticas administrativas das escolas e das redes públicas, indicam também que a mudança passa pelo reordenamento do trabalho educativo. No âmbito do presente estudo, destacaremos três aspectos centrais do pensamento pedagógico empresarial sobre o trabalho educativo. Ao longo da análise, nomearemos as organizações que se destacam nos temas selecionados.

\section{A) Sobre o lugar do trabalho educativo}

A questão que orienta nossa reflexão é a seguinte: como o pensamento pedagógico empresarial concebe a estrutura e a dinâmica do trabalho educativo? O primeiro ponto em comum às organizações empresariais estudadas ${ }^{6}$ é a defesa mais ou menos aberta do ordenamento hierárquico da divisão técnica do trabalho em três níveis.

No nível mais alto, concentram-se os formuladores dos instrumentos de avaliação da aprendizagem, responsáveis por estabelecer os parâmetros de aferição de eficiência do sistema educacional e as metas que devem ser alcançadas pelas unidades escolares das redes públicas. Nesse nível, reúnem-se também os responsáveis por conceber as práticas pedagógicas e de gestão julgadas como as mais eficientes, parametrizadas pelas avaliações e metas estabelecidas. No nível intermediário, encontram-se os líderes de equipe ou gerentes de unidades escolares, no passado, conhecidos como diretores, com a missão de assegurar que as referências administrativas e pedagógicas, além das metas externas, sejam alcançadas. Devem, ainda, traduzir diretrizes dos órgãos centrais de educação, incentivando a participação da comunidade escolar na execução dos programas ou projetos e implementando um conjunto de procedimentos administrativos e financeiros. No nível mais elementar, localizam-se os professores, responsáveis por traduzir, em sala de aula, todas as formulações produzidas no primeiro nível e repassadas pelos gestores e seus assessores (coordenadores pedagógicos). A eficiência do funcionamento da estrutura ou sistema educacional residiria na observância às funções previamente estabelecidas.

Entre as entidades estudadas, foi a Fundação Lemann, através de uma de suas intelectuais orgânicas, quem melhor traduziu a importância dos níveis hierárquicos na divisão técnica de trabalho educacional conforme a perspectiva empresarial. Guiomar Namo de Melo afirma que, para valorizar o trabalho educativo, o professor deveria ser isentado de planejar suas atividades docentes. Sua energia precisaria ser direcionada para a execução do planejamento e atendimento das necessidades de aprendizagens dos estudantes em sala de aula. Afirma também que a autonomia de trabalho do professor seria ampliada se ele fosse desocupado das exigências que, hoje, envolvem o seu fazer, para, então, se concentrar nos procedimentos técnicos de seu trabalho?

Portanto, os empresários defendem que a divisão técnica do trabalho na educação deve reproduzir a hierarquia e a estrutura de poder constitutivas da divisão social do trabalho, 
em geral, predominante em nosso tempo. Significa que o professor deve se tornar especializado em executar tarefas técnicas de ensino, cabendo à equipe de gestão controlar o trabalho realizado, considerando as referências estabelecidas pelo núcleo estratégico. A proposta empresarial de divisão parcelar do trabalho, algo típico do universo industrial, supõe o aumento da produtividade e da eficiência das redes públicas de ensino. Nessa concepção, há o predomínio da divisão entre concepção e execução do trabalho.

A divisão técnica do trabalho na educação e a noção de autonomia do professor, contidas nas formulações do pensamento pedagógico empresarial, buscam redefinir os fundamentos do trabalho educativo: de tipo artesanal a industrial. Sobre ele, incide uma posição normativa e prescritiva estabelecida pela estrutura hierárquica da divisão técnica. As ações da Fundação Lemann (2012) sobre gestão da sala de aula, traduzidas no curso de "técnicas didáticas", são exemplares para ilustrar essa formulação, bem como as intervenções da Fundação Vale/CEDAC por meio de seu projeto "Escola que Vale" (FUNDAÇÃO VALE/CEDAC, 2002).

Cabe ressaltar que a estratégia para a redefinição da natureza do trabalho educativo vem sendo defendida por meio de argumento refinado: a valorização da profissionalidade docente. Esse constructo significa o desenvolvimento de novas competências e habilidades referenciadas na racionalidade instrumental a partir da divisão técnica do trabalho acima delineada.

B) Sobre as finalidades do trabalho educativo

As formulações empresariais sobre a finalidade do trabalho educativo são também significativas. A questão destacada nesse item pode ser assim descrita: qual é a finalidade do trabalho educativo à luz do pensamento pedagógico empresarial?

As organizações empresariais afirmam que a escola pública deve cumprir uma dupla finalidade: formar "mão de obra" e formar para a cidadania, considerando os desafios do mundo atual. Para tanto, o professor deve ensinar bem, segundo os parâmetros de qualidade pré-definidos. Isso significa que o docente deve ser preparado em serviço e continuamente para se apresentar com nível de excelência. No pensamento pedagógico empresarial, é preciso que o trabalho educativo seja ordenado mais pelo treinamento técnico do que pela reflexão pedagógica, evitando assuntos não relacionados diretamente ao conteúdo que se deve ensinar.

Em relação à formação para os desafios, vinculam a importância do trabalho educativo e a formação escolar ao desenvolvimento econômico e à promoção da coesão social. A formulação da Confederação Nacional da Indústria (CNI, 2007, p.1) é emblemática nesse sentido, quando afirma que "A educação é uma das vertentes fundamentais para o crescimento da economia".

Vale lembrar que o empresariado brasileiro, ao longo do século $\mathrm{XX}$, optou por projetos de desenvolvimento que asseguraram a subordinação internacional do Brasil. No século XXI, verificamos que houve poucas mudanças. Essa classe considera que os países centrais que mais avançaram na corrida científica e tecnológica atingiram patamares inalcançáveis. Para os que amargaram o atraso em tal corrida, caberia o reposicionamento estratégico em busca de vantagens relativas, isto é, concentrar seus esforços na área das inovações e/ou na capacidade de aplicação das tecnologias de ponta para ampliar o mercado interno e abrir novas fronteiras comerciais.

Apontando que a capacitação do trabalhador seria um obstáculo ao uso de tecnologias e práticas inovadoras, caberia ao trabalho educativo promover o capital humano desses sujeitos, preparando-os para a nova realidade. Além disso, o trabalhador precisaria ter 
competências sociais, o que exigiria a promoção do capital social para transformá-lo em cidadão-colaborador. As formulações da CNI (2007) analisadas na pesquisa apontam nessa direção.

Segundo a visão empresarial, a finalidade do trabalho educativo, portanto, é desenvolver o capital humano e social a partir de um currículo prescrito. Nessa linha, o professor deve se subordinar aos parâmetros curriculares e, principalmente, à lógica das avaliações externas no tratamento do conhecimento para tornar a escola eficaz. Cabe esclarecer que se trata de uma tentativa de reordenar o trabalho do professor, para que atue rumo ao desenvolvimento da racionalidade instrumental dos alunos no processo de incorporação de certos valores morais. Ainda que não tenha clareza de sua função dentro do projeto empresarial de formação humana, o docente que segue essa linha tende a se configurar como intelectual orgânico da classe empresarial, contribuindo para ordenar o sentir, o pensar e o agir dos estudantes em consonância com o projeto dominante de sociabilidade.

A proposta da Fundação Lemann para a formação em serviço é exemplar. Para ela, o ensino deveria se distanciar das ideologias (visões de mundo) para padronizar o processo de trabalho e a formação dos estudantes. Nessa linha, a Fundação Lemann vem difundindo o manual de ensino do estadunidense Doug Lemov, intitulado Teach like a Champion ("Ensine como um Campeão"), traduzido para a língua portuguesa como: Aula Nota 10 - 49 técnicas para ser um professor bom de audiência. Com base em Lemov (2011), a Fundação Lemann acredita que o bom ensino se estrutura por meio de técnicas universais testadas e aprovadas por "especialistas".

Avaliamos que tais orientações interferem na subjetividade e identidade do professor e nas relações pedagógicas, na medida em que estabelecem a tecnificação e a rotinização do trabalho educativo de modo que o conhecimento e a reflexão perdem espaço. Além disso, aprofundam ainda mais a tendência de afirmação do nexo instrumental entre trabalho e educação já presente em nossa sociedade. Com efeito, o trabalho educativo - processo cultural específico destinado à formação do ser humano a partir da apropriação crítica e ativa do conhecimento sistematizado - é reduzido ao treinamento de competências e habilidades consideradas funcionais ao mercado de trabalho.

C) Sobre a organização do trabalho educativo

O terceiro e último aspecto que destacamos para apresentar a forma como o pensamento pedagógico empresarial concebe o trabalho educativo é orientada pela seguinte questão: quais são as propostas do empresariado para a organização do trabalho pedagógico?

Verificamos que as formulações empresariais sobre a organização do trabalho pedagógico se vinculam objetivamente à noção de produtividade e controle. No mundo dos negócios, a produtividade é mensurada levando-se em conta, basicamente, a redução do tempo e os custos da produção combinada com a manutenção ou elevação da qualidade do produto ou serviço final. É mais eficiente, portanto, mais produtiva, a empresa que consegue obter taxas de retorno (lucro) mais elevadas e rápidas frente aos investimentos e custos de produção. O processo produtivo de tipo industrial, por exemplo, ainda que dependa dos consumidores finais, é fechado ou programado, pois se tem controle preciso e minucioso de todas as suas etapas. Assim, o controle minucioso se torna algo estratégico para o sucesso dos negócios na medida em que permite a reprogramação de fases do processo.

Aplicadas à educação, a noção de eficiência se vincula à tentativa de medir o rendimento do sistema educacional, tendo em vista os investimentos que são realizados. É 
mais eficiente aquele sistema em que os alunos apresentam performances compatíveis ou superiores em relação ao montante de financiamento.

Para as organizações empresariais, os instrumentos de avaliação de desempenho dos estudantes não são suficientes, pois revelam somente a etapa final de um ciclo de escolarização. Como não se pode impedir que alunos com baixo capital cultural se matriculem nas escolas, a proposta envolve a utilização de outro mecanismo: o controle sobre o trabalhador docente.

As organizações partem do pressuposto de que a eficácia do trabalho educativo independe do número de alunos por sala e do tipo de recurso disponível. O que marca a diferença entre o ensino eficaz e o não eficaz seria a postura do professor diante de seus alunos. Sendo assim, a saída seria controlar a qualidade do trabalhador docente. Duas medidas são apresentadas pelas organizações empresariais.

A primeira delas envolve o processo de certificação de competências dos professores, uma espécie de atestado obtido por meio de provas que evidenciaria o potencial de eficácia do trabalho educativo. Os que obtiverem índices satisfatórios teriam asseguradas a progressão na carreira e algumas vantagens salariais.

Analisando criticamente essa formulação, que também é defendida pelo Banco Mundial, Shiroma e Schneider (2008) revelam que a certificação de professores expressa a tentativa de isentar o fundo público estatal da responsabilidade de prover as questões sociais para responsabilizar o professor pelo sucesso ou fracasso da educação pública. Segundo as autoras, trata-se de uma proposta política inspirada na "lógica competitiva do mercado, pautada sobre a noção de competência individual" (SHIROMA e SCHNEIDER, 2008, p. 42), cuja referência, a nosso ver, está alicerçada no modelo de Estado gerencial.

A segunda medida se refere à responsabilização do professor e dos diretores pelo desempenho dos estudantes, aferido nas avaliações em larga escala. Trata-se de uma interpretação do accountability ou política de responsabilização, que na visão empresarial significa um mecanismo para premiar ou punir, na linguagem empresarial "incentivar", cada professor ou coletivo de uma escola em função do desempenho dos alunos. Isso envolve assegurar autonomia das unidades escolares para que seus gerentes (ou diretores) possam tomar todas as medidas necessárias, inclusive demissão e contração de pessoal. As formulações da Fundação Itaú Social, sistematizadas por Gall e Guedes (20--), são significativas nesse aspecto.

Outra formulação importante é apresentada pelo organismo Parceiros da Educação. Entre outras idéias, defende que a contratação de professores deveria seguir regras mais flexíveis, ficando os contratos vinculados à capacidade meritocrática de cada professor. Nessa linha, o organismo acredita que a remuneração dos professores deveria ser afirmada nas seguintes bases: "parte fixa e outra variável, dependendo do desempenho (medido pelo aproveitamento escolar dos seus alunos)" (PARCEIROS DA EDUCAÇÃO, 2010, p. 6). Propõe também que as promoções sejam "respaldadas pelo desempenho em sala de aula e baseadas em claros padrões de excelência conhecidos sobre o que significa ser um 'bom' versus um 'excelente' professor" (PARCEIROS DA EDUCAÇÃO, 2010, p. 6). Em linhas gerais, não só o salário e a progressão estariam subordinados à produtividade do trabalho, mas, também, a manutenção do contrato se vincularia à eficácia do professor.

Tais formulações procuram indicar que é possível controlar o trabalho educativo por parâmetros semelhantes àqueles utilizados para medir a produtividade no mundo dos negócios. A despeito das consequências pessoais e das responsabilidades do Estado na política de valorização do trabalhador docente, a classe empresarial quer oferecer objetividade para controlar a organização e dinâmica do trabalho educativo, transformando o professor em um intelectual orgânico de seu projeto de dominação. 


\section{Considerações finais}

A classe empresarial que, no século XX, havia atuado politicamente para restringir o acesso aos níveis mais elevados da formação escolar por parte das massas trabalhadoras passou, no século XXI, a adotar outra estratégia, a de defender a educação básica. Porém, sua defesa visa legitimar o entendimento de que o sucesso do sistema educacional passa pela incorporação dos parâmetros gerencialistas, no sentido de situar a educação como instrumento para elevar a produtividade da força de trabalho e assegurar a coesão social. Isso significa que a posição dos empresários se distancia qualitativamente da noção clássica de educação enquanto direito social.

As reflexões apresentadas neste texto evidenciaram que a classe empresarial está empenhada em redefinir a natureza e a especificidade do trabalho educativo para reduzi-lo a um trabalho não autônomo, de tipo industrial, independente das consequências negativas que isso possa causar sobre o professor e os estudantes. Compreendendo a necessidade de organização para afirmar seus interesses coletivos, a classe empresarial tem recorrido a seus intelectuais, pessoas e organismos, que assumem o papel de organizar, elaborar e difundir sua concepção de educação escolar em prol da redefinição do trabalho educativo. Assim, visam subordinar a ação docente ao seu projeto de educação e sociedade, para que os professores possam contribuir para ordenar o sentir, o pensar e o agir dos alunos em conformidade com o projeto dominante de sociabilidade. Não obstante, parte das formulações empresariais analisadas neste texto já se expressa nas políticas públicas de educação no Brasil.

É certo que a educação brasileira enfrenta muitos problemas e parte deles se vincula ao trabalho realizado por professores. No entanto, culpar o professor e reordenar a natureza e especificidade do trabalho educativo tal como proposto pela classe empresarial é uma opção política que ataca os efeitos aparentes e não as causas essenciais do problema, além do que, se constitui como ação estratégica do empresariado na luta pela afirmação de seus interesses de classe.

Acreditamos que a elevação da qualidade educacional no país exige outras medidas que não podem ser respondidas pelo pensamento empresarial, sobretudo em razão de seu pragmatismo. O ponto de partida para mudanças essenciais exige o reconhecimento da natureza e especificidade do trabalho educativo e da finalidade da educação escolar, o que implicaria a adoção de ações de curto prazo, como melhores salários e condições de trabalho para os professores, mas, também, de ações de longo prazo, como transformações radicais na própria forma como homens e mulheres produzem sua existência, a fim de garantir melhores condições de vida a todos os seres humanos.

Se a classe empresarial tiver a força política para manter o gerencialismo como princípio organizativo da educação escolar e, ainda, a capacidade para ordenar o professor como organizador de base de seu projeto de sociabilidade, a educação escolar pública em nosso país estará a serviço do controle social, portanto, distanciada do preceito de emancipação humana.

\section{Referências:}

ALBUQUERQUE, R. C. O plano decenal de educação para todos e a estratégia nacional de desenvolvimento. Em Aberto. Brasília: Inep, ano 13, n. 59, p. 63-67, jul./set. 1993. 
CONFEDERAÇÃO NACIONAL DA INDÚSTRIA. Educação para a nova indústria. Brasília: Confederação Nacional da Indústria, 2007.

FUNDAÇÃO LEMANN. Relatório de Atividades 2011. São Paulo: Fundação Lemann, 2012.

FUNDAÇÃO VALE; CEDAC. Programa Escola que Vale. Formação de Professores. São Paulo: CEDAC, 2002.

GALL, N.; GUEDES, P. M. A reforma educacional de Nova York. Possibilidades para o Brasil. São Paulo, Fundação Itau Social, [20--].

GRAMSCI, A. Cadernos do cárcere. Vol. 3. Maquiavel. Notas sobre o estado e a política. Rio de Janeiro: Civilização Brasileira, 2000.

HAYEK, F. A. O caminho da servidão. Rio de Janeiro: Expressão e Cultura, 1987.

LEMOV, D. Aula nota 10: 49 técnicas para ser um professor campeão de audiência. São Paulo: Da Boa Prosa/Fundação Lemann, 2011.

MALINI, E. O consenso como ponto de partida? Uma análise dos papéis desempenhados pelos atores participantes na formulação do plano de desenvolvimento da educação. Dissertação (Mestrado em Educação). Universidade Federal de Juiz de Fora, Juiz de Fora, 2009.

MARTINS, A. S. A direita para o social: a educação da sociabilidade no Brasil contemporâneo. Juiz de Fora: Editora UFJF, 2009.

MARX, K. O capital. Vol.1. São Paulo: Abril Cultural, 1983.

NEVES, L. M. W. (org.). A nova pedagogia da hegemonia: estratégias do capital para organizar o consenso. São Paulo: Xamã, 2005.

OLIVEIRA, D. A. A reestruturação do trabalho docente: precarização e flexibilização. Educação e Sociedade. Campinas, vol. 25, n. 89, p. 1127-1144, Set./Dez. 2004.

PARCEIROS DA EDUCAÇÃO. A transformação da qualidade da educação pública no Brasil. São Paulo, 2010. Disponível em: 〈http://www.parceirosdaeducacao.org.br〉. Acesso em 23 de fevereiro de 2013.

SANTOS, I. M. Política de financiamento da educação e participação da comunidade na gestão da escola. RBPAE, v.22, n.2, p. 315-329, jul./dez. 2006.

SAVIANI, D. Pedagogia histórico-crítica: primeiras aproximações. 9. ed. Campinas: Autores Associados, 2005.

SHIROMA, E. O; SCHNEIDER, M. C. Certificação e gestão de professores. Temas $e$ Matizes, n. 13, p. 39-48, 2008. 


\section{Notas:}

${ }^{1}$ Professor Adjunto da Faculdade de Educação da Universidade Federal de Juiz de Fora (UFJF). Integra o Núcleo de Estudos sobre Trabalho e Educação da UFJF e coordena o Coletivo de Estudos sobre Política Educacional. E-mail: <andre.martins@ufjf.edu.br>.

${ }^{2}$ Cursa Doutorado no Programa de Pós-graduação em Educação da Universidade Federal de Juiz de Fora com bolsa da Coordenação de Aperfeiçoamento de Pessoal de Nível Superior (CAPES). Integra o Núcleo de Estudos sobre Trabalho e Educação da UFJF. E-mail: <leodocena @ yahoo.com.br>.

${ }^{3}$ Cursa Mestrado no Programa de Pós-graduação em Educação da Universidade Federal de Juiz de Fora com bolsa da Coordenação de Aperfeiçoamento de Pessoal de Nível Superior (CAPES). Integra o Núcleo de Estudos sobre Trabalho e Educação da UFJF. E-mail: 〈luciaavila_jc@yahoo.com.br〉.

${ }^{4}$ Cursa Mestrado no Programa de Pós-graduação em Educação da Universidade Federal de Juiz de Fora. Integra o Grupo de Trabalho, Movimentos populares e Educação (TRAME) e o Núcleo de Estudos sobre Trabalho e Educação da UFJF. E-mail: <raiza.d.almeida@ hotmail.com>.

${ }^{5}$ O Fórum funciona sob os auspícios do Instituto Nacional de Altos Estudos - INAE. Esse organismo, conforme a acepção gramsciana, é um aparelho privado de hegemonia, criado em 1991, para oferecer base organizacional ao Fórum e sua efetividade, continuidade e permanência no cenário nacional. Encontra-se em atividade nos anos 2000, podendo ser acessado em: 〈http://www.forumnacional.org.br〉.

${ }^{6}$ Conforme mencionado, as organizações estudadas foram: Fundação Itaú Social, Fundação Vale, Fundação Lemann, CENPEC, Fundação Victor Civita, Todos pela Educação, Confederação Nacional das Indústrias e Parceiros da Educação.

7 A formulação de Guiomar Namo de Melo pode ser vista no vídeo disponível em: 〈http://www.youtube.com/watch?v=5QEk5-cPIdQ〉.

Recebido: $\quad$ março-14 $\quad$ Aprovado: julho-14 